\title{
Gastric emptying of barium sulphate suspension compared with that of water
}

\author{
N. RAMSBOTTOM, M. T. KNOX, AND J. N. HUNT \\ From the Department of Physiology, Guy's Hospital Medical School, London
}

SUMMARY Test meals consisting of water or a suspension of barium sulphate were given to two normal subjects. The rates of decrease of the volume of the gastric contents were indistinguishable for the two meals.

Interest in the effect of barium on gastric emptying arose because we were unable to confirm that metoclopramide increased the rate of gastric emptying (Margieson et al., 1966; James and Hume, 1968). In our studies we used a variety of aqueous solutions (Ramsbottom and Hunt, 1970), whereas the earlier authors had used barium meals. In the present study we found that water and a suspension of barium sulphate, specific gravity 1.36 , left the stomach at equal rates.

\section{Method}

\section{SUBJECTS}

The subjects taking part in these experiments were two men with no radiological evidence of gastrointestinal disease.

THE MEALS

Test meals consisted of either $250 \mathrm{ml}$ distilled water; or $250 \mathrm{ml}$ barium sulphate suspension prepared by mixing $125 \mathrm{ml}$ distilled water with $125 \mathrm{ml}$ Micropaque. The specific gravity of the resulting suspension was 1.36 and osmolarity $46 \mathrm{mmol} / 1000 \mathrm{~g}$ water.

All meals were given at room temperature.

\section{EXPERIMENTAL PROCEDURE}

Between 7 and 8 am each subject swallowed a rubber tube $80 \mathrm{~cm}$ in length and with a $3 \mathrm{~mm}$ bore. They washed out their stomachs by drinking $250 \mathrm{ml}$ tap water and completely aspirated the gastric contents. After the washout one of the above meals was instilled into the stomach down the tube. After

Received for publication 23 December 1976 a fixed time interval, which varied between one and 15 minutes, the gastric contents were completely aspirated, and the volume of the aspirate measured and recorded. A further wash was given to check that aspiration was complete. Throughout the experiments the subjects remained seated.

\section{Results}

In Figs 1 and 2, the volumes of the gastric contents were plotted against the time interval between instilling and recovery of the meals. This relation appears to be linear. Lines were then fitted to the results for each type of meal. The regression constants are shown in the Table.

It can be seen that intercepts and the slopes for

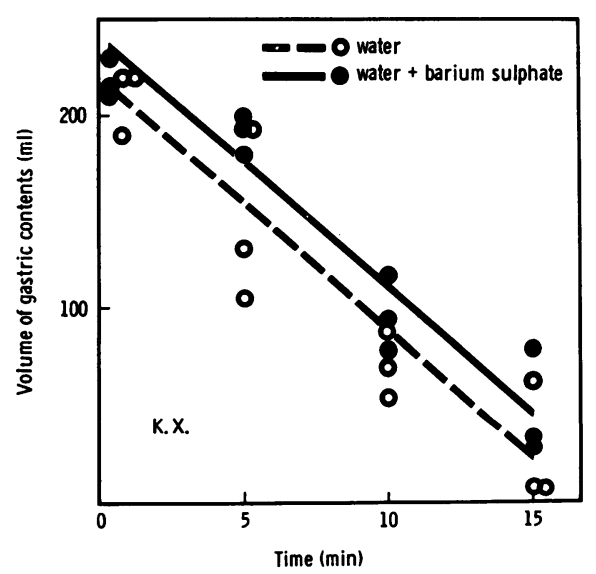

Fig. 1 The volumes of gastric contents recovered from the stomach after varying intervals of time in subject $K X$. 


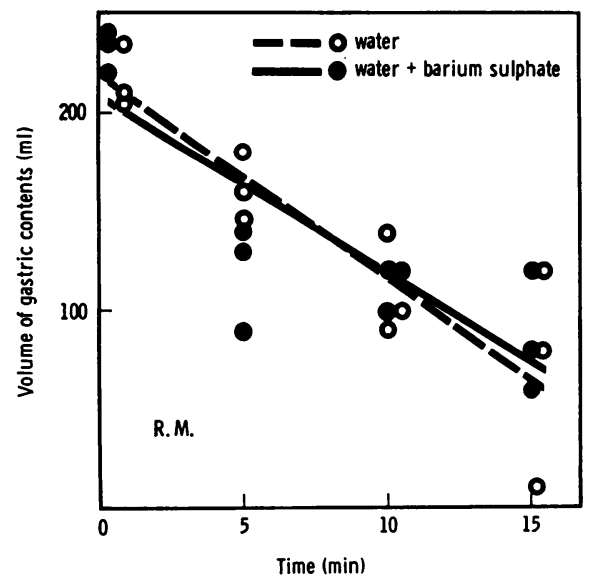

Fig. 2 The volumes of gastric contents recovered from the stomach after varying intervals of time in subject $R M$.

Table Volumes of meals recovered plotted against time between instilling and recovery of meals

\begin{tabular}{llllll}
\hline Subject & $\begin{array}{l}\text { Type of } \\
\text { meal }\end{array}$ & $a$ & $b$ & $S E$ of $b$ & $\begin{array}{l}\text { No. of } \\
\text { observations }\end{array}$ \\
\hline KX & Water & 217 & -13.0 & 1.54 & 12 \\
KX & Barium & 239 & -12.9 & 1.12 & 12 \\
RM & Water & 219 & -10.4 & 1.68 & 12 \\
RM & Barium & 209 & -9.1 & 1.99 & 12 \\
\hline
\end{tabular}

$y=a-b x$.

$y=$ volume of gastric contents.

a [intercept] = volume calculated to be recovered at zero time.

b [slope] = rate of fall in volume of gastric contents [ml/min].

barium suspension and water meals are virtually identical.

\section{Discussion}

Using the test meal method a large range of substances either in solution or suspension have been shown to alter the rate of gastric emptying relative to water (Hunt and Knox, 1968). However, to our knowledge, no attempt has been made to quantify the emptying of barium sulphate suspensions, which is of concern to the radiologist. Under our conditions the rate of fall of the volume of the gastric contents was not influenced by the presence of barium sulphate. We measured the volume of the gastric contents because that is what the radiologist assesses. It could be argued that the more rapid emptying of the barium suspension was offset by the increased rate of gastric secretion. From published results (Hunt, 1951; Hunt and Macdonald, 1952) we judge the volume of secretion in the gastric contents to be about $10 \%$ of the total at 15 minutes. It seems unlikely that changes in this small percentage would have much influence on the results.

It appears that the specific gravity of the gastric contents does not affect the rate of gastric emptying, at least when the subject is sitting in the upright position.

\section{References}

Hunt, J. N. (1951). The secretory pattern of the stomach of man. Journal of Physiology, 113, 169-184.

Hunt, J. N., and Knox, M. T. (1968). Regulation of gastric emptying. In Handbook of Physiology-Alimentary Canal, vol 4, p. 1917. Edited by C. F. Code. American Physiological Society: Washington.

Hunt, J. N., and Macdonald, I. (1952). The relation between the volume of a test meal and the gastric secretory response. Journal of Physiology, 117, 289-302.

James, W. B., and Hume, R. (1968). Action of metoclopramide on gastric emptying and small bowel transit time. Gut, 9, 203-205.

Margieson, G. R., Sorby, W. A., and Williams, H. B. L. (1966). The action of metoclopramide on gastric emptying: a radiological assessment. Medical Journal of Australia, 2, 1272-1274.

Ramsbottom, N., and Hunt, J. N. (1970). Studies of the effect of metoclopramide and apomorphine on gastric emptying and secretion in man. Gut, 11, 989-993. 